\title{
MANAJEMEN PENDIDIKAN ANAK DALAM KELUARGA
}

\author{
Aimi \\ Dosen Politeknik Negeri Sriwijaya \\ Email : aimimpdi@gmail.com
}

DOI : 10.35908/jeg.v4i2.760

Received: May 18, 2019, Revised: June 11, 2019, Accepted: July 07, 2019

\begin{abstract}
"The concept of Child Education Management according to the Qur'an". The Qur'an is a revelation of God which was revealed to Prophet Muhammad as the eternal miracle of all time. The Qur'an is the Holy Book of the Muslims which contains guidelines for a happy life and guidance of the world and the hereafter. It contains worship, morals, exemplary story, occult news, universe and so on. Even the Qur'an mentions that It also functioned as an explanation of all things (tibyanan likulli sya-in) (QS. An Nahl/16:89). This reaffirms that there is no exception, everything in the universe has its explanation from the Holy Qur'an. No exception regarding family issues, especially related to parenting and education for children who grew up in his family environment. The main problems in this research is how is the concept of child education management according to the Qur'an in the family? In line with that, the Holy Qur'an encourage every parent to feel worried, if then behind the day after, they left a weak generation (QS. An Nisa 1/4:9). This is the requirement so that each moslem parent are able to manage their children's education so they can grow and develop a

as their expectations, well educated, have a tough faith, good morals and have the skills to live independently. For that, it needs a pattern and attempts so that the process can go as desired. The method used in the writing of this thesis is the method of thematic tafseer (maudhu'i). And the purpose of the research is to be able to find the concept of child education management in a family that Qur'anic. Ultimately it is hoped that the concept of child education management within the family based on the Qur'an will be the solution to achieve the goals of parents to have pleasant children (QS. Al Furqan/25:74), starting with the planning (planning) (QS. Al Anfal/8:60), organizations (organizing) (QS. Ash Shaff/61:4), applications (actuiting) (QS. At-Tawba: 105/9) and control (controlling) (QS. QAF/50:16-18). The four stages above, are big agendas for each moslem family in order for their children to become shalih and shalihah. Good cooperation between husband and wife in dividing duties and obligations as a father and mother became the key word in determining the success of the process of upbringing and education of their children to become a perfect human being as they expected.
\end{abstract}

\section{Key Word: Management, Education, Child, and Family}

\begin{abstract}
ABSTRAK
“Konsep Manajemen Pendidikan Anak Menurut al Qur'an”. Al Qur'an merupakan wahyu Allah yang diturunkan kepada Nabi Muhammad SAW sebagai mukjizat yang kekasl sepanjang masa. Al Qur'an adalah kitab suci umat Islam yang berisi panduan dan tuntunan hidup untuk bahagia dunnia dan akhirat. Didalamnya berisikan tentang ketauhidan, ibadah, akhlak mulia, kisah teladan, berita ghaib, alam semesta dan lain sebagainya. Bahkan al Qur'an menyebutkan bahwa dirinya juga berfungsi sebagai penjelasan atas segalanya sesuatu (tibyanan likulli sya-in) (QS.An Nahl/16:89). Hal ini mempertegas bahwa tidak ada pengecualian semua yang ada di jagad raya ini ada penjelasannya dalam al Qur'an. Tak terkecuali mengenai masalah keluarga, utamanya berkaitan dengan pengasuhan dan pendidikan untuk anak-anak yang tumbuh dan besar di lingkungan keluarganya. Permasalahan pokok dalam penelitian ini adalah bagaimana konsep manajemen pendidikan anak menurut al Qur'an dalam keluarga? Sejalan dengan itu al Qur'an menghimbau agar setiap orang tua merasa khawatir, jika kemudian di belakang hari setelah sepeninggalnya, mereka meninggalkan generasi yang lemah
\end{abstract}


(QS.An Nisa'/4:9). Ini isyarat agar setiap orangtua muslim memanaj pendidikan anak-anaknya sehingga dapat tumbuh dan berkembang sesuai harapan mereka, terdidik dengan baik, memiliki keimanan yang tangguh,berakhlak mulia dan memiliki keterampilan hidup untuk mandiri. Untuk itu, dibutuhkan sebuah pola dan upaya agar proses itu berjalan sesuai yang dikehendaki. Metode yang gunakan dalam penulisan tesis ini adalah metoda tafsir tematik (maudhu'i). Dan tujuan penelitian ini adalah agar dapat menemukan konsep manajemen pendidikan anak dalam keluarga yang Qur'ani. Pada akhirnya diharapkan bahwa konsep manajemen pendidikan anak dalam keluarga berdasar al Qur'an akan menjadi solusi tercapainya cita-cita orangtua memiliki putera puteri yang menjadi penyeng=ang hati (QS.Al Furqan/25:74), dimulai dengan perencanaan (planning) (QS.Al Anfal/8:60), organisasi (organizing) (QS.Ash Shaff/61:4), aplikasi (actuiting) (QS.At Taubah/9:105) dan kontrol (controling) (QS.Qaf/50:16-18). Keempat tahapan di atas, menjadi agenda besar bagi setiap keluarga muslim agar putera puterinya menjadi anak yang shalil dan shalihah. Kerjasama yang baik antara suami dan isteri dalam membagi tugas dan kewajibannya sebagai ayah dan ibu menjadi kata kunci dalam menentukan keberhasilan proses pengasuhan dan pendidikan putera puteri mereka menjadi insan kamil sesuai harapannya.

\section{Kata Kunci: Manajemen, Pendidikan, Anak, dan Keluarga}

\section{A. Pendahuluan}

Otentisitas al-Qur'an sebagai kitab suci tentu tidak menyisakan ruang untukdiperdebatkan. Akan tetapi al-Qur'an sebagai sumber segala ilmu (QS. 6: 38) yang memuat dimensi epistemologis bagi pendidikan anak, hal ini perlu ditemukan dan dikembangkan, sebab al-Qur'an merupakan sumber dari segala seumber tertinggi baik hukum, ilmu, akhlak bahkan tata kelola rumah tangga serta pengelolaan pendidikan anak. Pendidikan Islam dengan karakteristik agama, menjadikan dasardasar agama sebagai landasan pendidikan bagi anak-anak sebagai generasi yang akan datang. Menurut Al-Nahlawi (2000, hlm. 28) Al-Qur'an, dan al-Sunnah sebagai asas pokok pendidikan Islam. Darajat (1999, hlm. 17) menambahkan dengan qaul sahabat, masalih al-Mursalah dan urf. Berdasar pada uraian tersebut, maka pemaknaan terhadap nilai sejarah dalam al-Qur'an, di antaranya kisah-kisah yang dapat didekati dengan perspektif pendidikan anak, menjadi sebuah keniscayaan untuk dikaji.

Anak dalam berbagai prosesnya memerlukan kebutuhan berupa perawatan, bimbingan pengembangan segenap potensinya kepada tujuan yang benar. Ia harus dikembangkan dalam kerangka positif melalui suatu upaya yang disebut sebagai al-tarbiyah, al-ta'dib dan alta'lim. Realitasnya kemudian dengan alasan kesibukan, keterbatasan waktu dan kemampuan orang tua terkadang menjadi faktor mendasar untuk memasukkan anak pada lembaga pendidikan. Ditambah kurangnya pengetahuan tentang perkembangan anak dan sumber belajar di rumah yang tidak memadai. Adanya tuntutan lembaga pendidikan setingkat di atasnya juga mendorong orang tua untuk menyekolahkan anak. Aspek lain menunjukkan bahwa kemajuan ilmu pengetahuan dan kecanggihan teknologi di era globalisasi dewasa ini hampir menjadikan dunia tidak ada batas antar wilayah dan negara. Hal ini berdampak masuknya budaya dan informasi dari negara lain ke dalam budaya lokal sangat mudah, bahkan tidak dapat dihindarkan. Baik melalui televisi, internet maupun media lainnya.

Hal lain yang muncul dalam realitas di tengah perubahan gelombang besar perkembangan dan kemajuan dunia teknologi dan informasi serta digitalisasi di 
era global dewasa ini telah banyak memberikan perbuahan pola asuh dan pola didik orang tua terhadap anak-anak. Tantangan dirasa semakin berat ketika hampir di setiap keluarga telah tersambung dengan dunia digital, baik itu dari tayangan televisi dengan beragam jaringan program, yang lebih banyak menyuguhkan acara orang dewasanya, ketimbang acara untuk anak-anak, belum lagi tayangan kekerasan, sadisme dan kebobrokan prilaku menyimpang lainnya, menambah lengkapnya beban berat yang dihadapi oleh setiap orang tua dalam impiannya untuk menjadikan putera-puterinya menjadi putera-puteri yang shaleh dan shalihah, berilmu, dan berakhlak mulia. Ditambah lagi dengan dunia maya internet yang juga menyuguhkan berbagai websitenya, yang tidak semuanya layak di konsumsi bagi anak-anak (Tjiptoherijanto dan; Nagib, 2008, hlm. 16-17). Gambaran semua kemajuan teknologi informasi diera globalisasi di atas, tentu bukanlah sesuatu yang harus dihindari atau ditolak kehadirannya, tetapi perlu adanya pendidikan, antisipasi dan filter yang tepat dalam menghadapinya. Di sinilah letak pentingnya konsep manajemen pendidikan anak dalam keluarga menurut al-Qur'an. Al-Qur-an yang diturunkan Allah untuk manusia memiliki berbagai fungsi, diantaranya sebagai al Huda (petunjuk) (QS. Al Baqarah/2 : 2, 97, 185), (QS. Al Maidah/5 : 46).

Upaya menghadapi dan mengantisipasi tantangan diatas, maka pendidikan bagi anak seharusnya sudah dimulai sejak awal masa kanak-kanak (Susilo dan Kasihadi , 2008, hlm. 67) . Pada masa inilah saat yang paling tepat untuk meletakkan dasardasar "pendidikan" untuk persiapan menerima bekal pendidikan selanjutnya di sekolah. Umur tiga sampai tujuh tahun anak mulai sadar akan "akunya", kemauannya mulai tumbuh. Egonya mulai menguasai dirinya, setiap orang harus menuruti kemauannya, ia merasa berkuasa. Pada masa ono, anak sukar diarahkan, tetapi kritis menanyakan apa saja yang ia lihat. Namu ia sudah mulai dapat menguasai kebiasaan-kebiasaan tertentu yang positif (Hurlock, tt, hlm. 10). Diasmping itu, maka kanak-kanak merupakan masa yang sangat sensitive dan masa meniru, karena itu maka pendidikan harus berupaya menanamkan kebiasaankebiasaan yang baik, belajar menolong diri sendiri, dan sebainya (Derajat, 1977, hlm. 87). Dalam pada itu, setiap pengalaman yang dihadapi anak ketka melalui penglihatan, pendengaran, maupu perlakuan yang diterimanya, baik pengalaman yang pahirt maupun yang menyenangkan dalam hidupnya, ikut menjadi bagian yang membentuk pribadinya. Pengalaman-pengalaman tersebut meliputi pendidikan yang diterima, perlakuan orangtua, serta sikap orangtua terhadap si anak. Maka sia anak yang sering mendengar orangtua mengucap nama Allah SWT., majka ia akan mulai mengenal Allah, yang kemudian dapat menolong pertumbuhan jiwa keagamaannya dan merupakan bibit dalam pembinaan jiwanya (DErajat, 1977, hlm. 60).

Lebih lanjut sejak awal, pendidikan terhadap anak yang sudah dimulai sejak masa awal kehidupan anak adalah lebih utama, karena pada masa kecil itu anak memiliki Ingatan yang cemerlang dan masih kuat . Prnyataan ini didasarkan pada sabda Rasulullah SAW. yang menggambarkan betapa proses transfer ilmu dan pembentukan karakter lebih 
mudah dilakukan pada masa kanak-kanak disbanding pada masa dewasa. Rasulullah SAW. bersabda ; perumpamaan orang yang menuntut ilmu (yang dimulai) sejak kecil bagaikan mengukir diatas batu, dan perumpamaan orang yang menuntut ilmu ketika ia telah dewasa bagaikan menulis di atas air. (Hadits Riwayat al-Tabrai dalam Ali Ibn Abi Bakr al-Haysami) (Majma' azzawa'id, th. 1407 H., Jus I, hlm. 125). Tiga tahun pertama umur sang anak merupakan basis dan masa yang subur bagi pembinaan yang kita khendaki dan rencanakan bagi perkembangan anak di masa mendatang. (Qutub, tt, hlm. 77) Maka dari itu sudah seharusnya dalam usia ini, pendidikan anak sudah diperhatikan dan ditangani secara serius agar potensi-potensi yang dimiliki anak nantinya dapat berkembang secara optimal sehingga diharapkan akan membuahkan hasil yang menggembiraka di masa berikutnya. Anak harus diperhatikan kebutuhan jiwa dan sosialnya. Maka perlakuan orangtua terhadap anak dikatakan baik apabila kebutuhan pokok si anak terpenuhi semuanya. Kebutuhankebutuhan jiwa, seperti kasih sayng, rasa aman, harga diri, kebebasan dan lainnya harus diperhatikan secara seksama. Dengan demikian agar anak bahagia kebutuhan dasar dan jiwanya harus terpenuhi (Hurlock, tt, hlm. 40)

\section{B. Perumusan dan Pembatasan Masalah}

\section{Rumusan Masalah}

1. Apa yang dimaksud dengan mendidik anak dalam keluarga berdasarkan al-Qur'an?

2. Bagaimana manajemen pendidikan anak dalam keluarga menurut alQur'an?
3. Bagaimana konsep al-Qur'an dalam penerapan manajemen pendidikan anak?

\section{Batasan Masalah}

Luasnya penelitian tentang konsep pendidikan anak, baik di rumah, sekolah dan lingkungan dimana anak itu tumbuh dan besar, maka mengharuskan penulis untuk membatasi ruang lingkup yang diteliti. Pada penelitian yang menulis anak dalam keluarga menurut al-Qur'an. Hal ini dikarenakan masa pendidikan, bimbingan dan asuhan bagi anak dalam keluarga adalah masa yang sangat urgent dan fundamental sebagai dasar pendidikan selanjutnya. Dan akan sangat berpengaruh terhadap masa depan anak yang bersangkutang. Karena pada masa itu ada masa golden age untuk proses sebuah pendidikan yang sangat dibutuhkan anakanak.

\section{Tujuan Penelitian}

1. Mengetahu konsep manajemen mendidik anak dalam keluarga menurut al-Qur'an

2. Menjelaskan konsep manajemen pendidikan anak dalam keluarga menurut al-Qur'an

3. Menemukan konsep manajemen pendidikan anak dalam keluarga yang Qur'ani. Yang pada akhirnya diharapkan bahwa konsep manajemen pendidikan anak dalam Keluarga berdasar al Qur'an akan menjadi solusi tercapainya cita-cita orangtua memiliki putera puteri yang menjadi penyenang hati (QS.Al Furqan/25:74).

4. Mengetahui tahapan aplikasi konsep manajemen mendidik anak yang Qur' ani dalam keluarga 


\section{Kegunaan teoritis}

1. Penelitian ini berguna untuk membangun manajemen pendidikan anak dalam keluarga berdasarkan nash (al Qur'an)

2. Memperkaya khazanah literature tentang manajemen pendidikan anak berdasarkan nash (al Qur'an)

\section{Kegunaan Praktis}

1. Hasil studi ini juga dapat dijadikan salah satu khazanah mengembangkan model pendidikan anak dalam keluarga berdasarkan nash (al Quran dan al Hadits)

2. Mengetahui lebih dalam tentang konsep manajemen pendidikan anak dalam keluarga menurut al Qur'an dan al Hadits.

\section{Kajian Teori}

Dalam studi ini menggunakan teori interaksi simbolik (symbolic interaction) yang diperkenalkan pertama sekali George Herbert Mead (1969). Pemahaman atas teori tersebut bahwa manusia adalah makhluk individu dan makhluk social. Dalam hubungannya dengan manusia sebagai makhluk sosial, terkandung suatu maksud bahwa manusia bagaimanapun juga tidak dapat terlepas dari individu yang lain. Secara kodrati manusia akan selalu hidup bersama. Hidup bersama antar manusia akan berlangsung dalam berbagai bentuk komunikasi dan situasi. Dalam kehidupan semacam inilah terjadi interaksi. (Soeprapto,2002,hlm. 108; Sardiman, 2000, hlm.1). Teori interaksionisme simbolik mempelajari sifat interaksi yang merupakan kegiatan dinamis manusia. Bagi perspektif ini, individu bersifat aktif, reflektif dan kreatif, menafsirkan, menampilkan perilaku yang rumit dan sulit diramalkan. Menolak gagasan bahwa individu adalah pasif yang perilakunya ditentukan oleh kekuatankekuatan struktur yang ada di luar dirinya. Interaksilah yang dianggap penting yang menentukan perilaku manusia, bukan struktur masyarakat (Don, 2006, hlm.125).

\section{Metode penelitian}

Sesuai dengan sifatnya penelitian ini, bercorak penelitian kepustakaan (Library Research) maka yang menjadi sumber data utama adalah menekankan pada pengungkapan makna tes suci (scriptular texts) dengan perspektif interaksi pendidikan anak. Penelitian ini termasuk penelitian kualitatif dan menggunakan metode tafsir (exegesis) tematik (maudhu'i). Metode tafsir ini dipilih,diharapkan agar memperoleh jawaban secara tuntas tentang suatu persoalan, sehingga mampu menjawab dan menolak adanya kesan kontradiksi diantara ayat-ayat al Qur'an. Metode tematik ini digunakan untuk identifikasi ayat-ayat alQur'an yang memuat manajemen pendidikan anak, selanjutnya pemahaman ayat ayat tersebut dikembangkan dengan pendekatan langsung dan holistic.

Pendekatan langsung adalah suatu cara kerja memahami obyek dengan langsung kepada obyek dengan langsung kepada obyek terkait. Dalam kajian tafsir al Qur'an , pendekatan ini disebut pendekatan Qur'ani (Qur'ani approach). Dikatakan demikian karena penelitian mencari kandungan Al Qur'an langsung ke dalam obyek penelitian yaitu ayat-ayat AlQur'an . hal ini berfungsi untuk proses menuju pemahaman secara komprehensif 
makna yang terungkap dalam ayat AlQur'an untuk menemukan jawaban atas masalah yang dikaji.

(http://rampaitafsir.blogspot.com/)

\section{Jenis data}

1. Data primer

Dalam penelitian yang penulis lakukan ini sumber data primernya adalah ayat-ayat al-Qur'an yang berkaitan dengan pendidikan, anak dan keluarga. Kemudian mengumpulkannya selanjutrnya diolah (dirujuk tafsirnya) dan dianalisa sesuai kontek kajian dan pembahasannya.

\section{Data Sekunder}

Adapun data pendukung yang penulis gunakan adalah bersumber dari hadits-hadits Nabi saw. Yang relevan dengan permasalahan, kajian dan pembahasan untuk lebih memberikan kejelasan tentang maksud ayat yang sedang dikaji. Selain itu penulis juga menggunakan rujukan kitab tafsir dan buku lainyang relevan dengan penelitian yang penulis lakukan.

Teknik Analisa Data

Teknik analis data dalam penelitian kualitatif sebagaimana yang penulis lakukan adalah didasarkan pada teori induksi. Artinya proses pengambilan keimpulannya melalui dinalisis data dengan tetap mepertahankan keaslian teks yang memaknainya. Hal ini dilakukan karena tujuan penelitian kualitatif adalah untuk memahami fenomena dari sudut pandang partisipan, konteks social dan institusional dan mengikuti langkahlangkah sebagai berikut :
1. Mengumpulkan dan menghimpun ayat-ayat al Qur'an yang relevan dengan tema pembahasan.

2. Menyusun ayat-ayat al-Qur'an secara sistematis menurut kerangka pembahasan yang telah direncanakan

3. Memberikan uraian dan penjelasan dengan menggunakan ilmu bantu yang relevan dengan masalah yang dibahas dengan dilengkapi memahami sebab turunnya (asbabun nuzul) dan hubungan (munasabat) ayat selama tidak mempengaruhi pengertian yang ditekankan dalam pembahasan dimaksud.

4. Menyimpulkan dan melahirkan konsep tentang manajemen pendidikan anak dalam keluarga menurut al Qur'an.

\section{PEMBAHASAN}

Dalam tafsiran jalalain, (20032007) disebutkan bahwa pertanyaaan itu bermakna menidakkan yaitu Dia (Allah) tidak akan mengadazabkan kamu. oleh karenanya Allah mensyurukuri hambahambanya dengan cara, memberi pahala terhadap amal-amal hamba-hamba-Nya, mema'afkan kesalahannya, dan menambah nikmat-Nya

"Dan sesungguhnya telah Kami berikan hikmah kepada Luqman, yaitu: "Bersyukurlah kepada Allah. Dan barangsiapa yang bersyukur (kepada Allah), maka sesungguhnya ia bersyukur untuk dirinya sendiri; dan barangsiapa yang tidak bersyukur, maka sesungguhnya Allah Maha Kaya lagi Maha Terpuji” (QS. Luqman/31 :12) dikarunianya keturunan adalah dengan cara mengasuhnya dan 
mendidiknya dengan podan manajemen yang Allah atur dalam kitabsuci-Nya. salah satu gambaran dalam tahap syukur itu dengan mengenalkan dan menanamkan nilai ketauhidan (ketuhanan), berbuat baik terhadap orang tua, penanaman rasa di awasi oleh Allah, pendidikan shalat, pendidikan amar ma'ruf nahi mungkar, larangan berlaku sombong dan perintah selalu berlaku sederhana baik dalam prilaku maupun ucapan.

Dari uraian di atas, maka syukur itu mencakup tiga sisi ;

1. Syukur dengan hati, yaitu kepuasaan batin dan anugerah, sehingga dia selalu mengingat Allah sebagai pemberi nikmat tanpa melupakannya.

2. Syukur dengan lidah (lisan), dengan mengakui anugerah dan selalu memuji pemberunya.

3. Syukur dengan perbuatan, dengan memanfaatkan anugerah yang diperoleh sesuai tujuan penganugerahnya.

Jika anak telah berumur tiga tahun, ajarilah ia kalimat "Laa ilaaha illallah" (tiada Tuhan selain Allah) sebanyak tujuh kali lalu tinggalkan ia. Saat ia berusia tiga tahun tujuh bulan dua puluh hari, katakan kepadanya "Muhammad Rasulullah" (Muhammad adalah utusan Allah) sebanyak tujuh kali, lalu tinggalkan sampai ia berumur empat tahun. Kemudian, ajarilah ia untuk mengucapkan "Shallallaah 'alaa Muhammad wa aalihi" (Salam sejahtera atas Muhammad dan keluarganya) sebanyak tujuh kali dan tinggalkan. Setelah ia genap berusia lima tahun, tanyakanlah kapadanya mana kanan dan mana kiri? Jika ia mengetahui arah kanan dan kiri palingkan wajahnya untuk menghadap kiblat dan perintahkanlah ia untuk bersujud lalu tinggalkan. Setelah ia berumur tujuh tahun suruhlah ia untuk mencuci wajah dan kedua tangannya dan perintahkanlah ia untuk shalat lalu tinggalkan. Saat ia berusia genap sembilan tahun ajarilah wudhu dan shalat yang sebenarnya dan pukullah ia bila meninggalkan kewajibannya ini. Jika anak telah mempelajari wudhu dan shalat dengan benar, maka Allah akan mengampuninya dan mengampuni kedua orang tuanya, Insya Allah. (http://www.alshia.org/html/id/books/Pendidikan Anak/07.htm\#_ftn26)

\section{Akhlak implementasi Kaedah Asasi dalam Pendidikan Anak}

Al Qur'an hadir membawa pencerahan bagi kehidupan manusia, utamanya berkaitan dengan akhlak. Allah menggambarkan tentang akhlak Nabi SAW dalam firman-Nya: "dan sesungguhnya kamu benar-benar berbudi pekerti yang agung." (QS. Al Qalam/68:4 "Adapun tabiat atau perangai yang memang sudah ada pada masing-masing orang disebut watak. Dari keterangan di atas dapat disimpulkan bahwa watak adalah sesuatu yang memang sudah ada pada masing-masing orang, sedangkan akhlak adalah sikap dan tindakan yang dapat di bina dan di ciptakan dalam diri masing-masing pribadi. Oleh karenanya, yang dibutuhkan oleh anak adalah pembinaan akhlak. Untuk mewujudkannya, dibutuhkan kerja keras dan kesabaran orang tua selaku pendidik. Terdapat banyak sekali ayat-ayat al quran yang mencerminkan tentang pentingnya penanaman akhlak pada anak-anak. Diantaranya adalah: 
1. Berbuat Baik Terhadap Orang tua

Orang yang beriman hendaknya bersyukur kepada Allah dan berterima kasih kepada orang tuanya karena pengorbanan orang tuanya yang telah menghabiskan begitu banyak waktu dan jerih payah untuk menjaganya bertahuntahun semenjak pertama kali membuka matanya di dunia ini Berkaitan dengan berbuat baik terhadap orang tua, dalam tafsir Ibnu Katsir (1999 hlm.608) disebutkan melalui ayat ini Allah memerintahkan dan memberikan tuntunan bahwa hendaknya setiap orang berbuat baik terhadap orangtuanya dengan sebaikbaik perlakuan. Selanjutnya agar manusia tidak mengatakan kepada kedua orangtuanya perkataan yang menyakitkan meskipun sekedar berkata "ah" yang merupakan perkataan buruk yang paling remeh. Kemudian, kalimat "janganlah kamu membentak mereka", maknanya agar anak tidak mengarahkan tangannya (menunjuk-nunjuk) dengan tidak sopan kepada orang tua.

\section{Akhlak Pergaulan di dalam Rumah}

Agar anak tumbuh menjadi pribadi yang mulia, al Qur'an memberikan tuntunan tentang tata pergaulan di rumah, Ibnu Katsir (1999 hlm. 756-757) menjelaskan tentang permintaan izin yang harus dilakukan oleh orang yang mempunyai hubungan kekerabatan satu sama lain, sedangkan yang disebutkan dalam permulaan surah adalah permintaan izin yang harus dilakukan oleh ajanib (orang yang tidak ada hubungan kekerabatan) satu sama lain. Dengan turunnya ayat ini, Allah SWT., memerintahkan kepada orang-orang yang beriman agar pelayan mereka dari hamba sahaya yang mereka miliki dan anak-anak mereka yang belum baligh meminta izin dalam tiga waktu;

Pertama, sebelum shalat subuh karena pada saat itu orang sedang terlelap tidur diatas kasur mereka. Kedua, seperti yang disebutkan dalam firman Allah, "kamu menanggalkan pakaian (luar)mu di tengah hari," yaitu ketika waktu qailulah (tidur singkat di siang hari), karena pada waktu itu terkadang orang-orang melepaskan pakaian mereka untuk istirahat bersama keluarga. Ketiga, seperti yang disebutkan dalam firman Allah, "dan setelah shalat 'Isya'," karena waktu tersebut adalah waktu yang dipergunakan untuk tidur.

2. Berlaku Adil dan Berbuat Baik Berlaku adil dan berbuat baik adalah sebuah keniscayaan dalam segala aspek kehidupan ini, terutama dalam proses pengasuhan dan pendidikan anak-anak. Allah berfirman Tugas penting selanjutnya yang menjadi tangggungjawa orang tua adalah mempersiapkan dan memelihara kesehatan fisik anak-anaknya. Mereka juga perlu diperkenalkan dan dilatih mempraktekan dam memperagakan berbagai jenis olahraga. Jika hali ini dibiasakan sejak usia kanak-kanak, maka fisik mereka lebih sehat, kuat dan kekar dengan pertumbuhan yang normal dan maksimal.

\section{Beberapa Metode Pendidikan Anak dalam Keluaraga}

1. pendidikan dengan nasehat ;

Termasuk metode pendidikan yang cukup berhasil dala m memprsiapkan baik secara moral, emosional , maupu sosial, adalah pendidikan anak dengan petuah dan memberikan kepada nasehat-nasehat 
Nasehat dan wasiat dalam al-Qur'an memberikan sandaran untuk para pendidik melakukan :

a. Pengarahan dengan Kata Penguat

b. Pengarahan dengan mengandung ancaman

c. Pengarahan dengan argumen logika

d. Pengarahan dengan yurisprudensi

Al-Qur'an penuh dengan ayat-ayat yang menjadikan metode pemberian nasehat sebagai dasar dakwah, sebagai jalan menuju perbaikan individu, dan memberi petunjuk bagi masyarakat. Metode al -Qur'an dalam menyajikan nasehat dang pengajaran mempunyai ciri tersendiri. Yaitu : seruan yang menyenangkan, seraya dibarengi dengan kelembutan atau upaya penolakan. Seperti contoh : a.Uslub untuk seruan kepada anak-anak b,.Uslub untuk wanita

2. Pendidikan dengan memberikan Hukuman

Dalam masalah hukuman harus ada perbedaan antar hukuman yang khusus dikeluarkan negara dan yang wajib diterapkan oleh kedua orang tua dalam keluarga dan para pendidik di sekolah. Untuk hukuman kepada anak diperlukan metode yang dipakai Islam, yaitu : Lemah lembut dan kasih sayang adalah dasar pembenahan anak. Menjaga tabi'at anak yang salah dalam menggunakan hukuman, artinya, anak-anak, dilihat dari kecerdasan berbeda, baik karakter maupun pemberian tanggapannya, berbeda juga dari segi pembawaan. Untuk pemberian hukuman diperlukan juga tinjauan karakter anak. Ada yang hanya dengan nasehat, ada yang cukup dengan teguran, namun ada juga yang sadar setelah mendapat pukulan.

\section{KESIMPULAN}

Al-Quran telah memakai hukuman yang memberikan ketakutan dan ancaman ini dalam banyak ayat yang jelas, dan menggunakannya dalam upaya memperbaiki jiwa yang mukmin, mempersiapkan moral dan spiritualnya. Betapa telah memberikan bekas dalam jiwa, hasil yang baik dalam tingkah laku, akibat-akibat terpuji dalam pendidikan dan etika Yang cerdas, berpengetahuan, berkpribadian serta produktif. Ini dimaksudkan agar keluarga muslim sanggup mengantarkan putera-puterinya menguasai dasar-dasar pengetahuan secara memadai, baik dalam bidang keimanan, ilmu, ibadah dan akhlak serta sebagai tempat pengemblengan diri untuk menumbuhkan semua potensi dan mengembangkan kreativitas, keterampilan dan etos kerja.Hendaknya dapat dan mampu merespon tuntutan-tuntutan masa depan. Untuk itu keluarga seyogyanya diarahkan untuk melahirkan sumber daya manusia yang memiliki kesiapan keimanan, ilmu, ibadah dan akhlak untuk memasuki era globalisasi, era industrialisasi dan era informasi sekarang ini. Sehingga pada akhirnya menjadi generasi terbaik yang siap melanjutkan estafet kepemimpinan serta menjadi tumpuan dalam memperbaiki bangsa ini.

Islam juga menghimbau agar seorang muslim makan dari penghasilan yang halal dan memberi makan istrinya dari yang halal pula. Sebab sperma yang kelak menghasilkan anak berasal dari darah, dan darah berasal dari makanan. Setiap daging yang tumbuh dari makanan yang haram hanya layak mendapat neraka, dan barang siapa yang diciptakan untuk neraka maka ia hanya akan mengerjakan amalan penghuni neraka. Sehingga jika 
sudah demikian halnya pendidikan dan penggemblengan jenis apapun tidak akan mampu dan berguna lagi. Hal lain, Islam menganjurkan suami istri untuk berdo'a saat melakukan hubungan seksual agar Allah menjauhkan hubungan mereka dari setan. Kemudian begitu merasa hamil, si ibu menghimbau untuk menggantungkan harapannya kepada Allah agar janin yang dikandungnya kelak menjadi orang yang saleh dan bersih di masa depan. Disunahkan pula selama hamil, ibu kadang perlu menolak dan melawan keinginan hasratnya akan hal-hal yang disukainya,sebab janin adalah bagian dari dirinya,dan iapun akan ikut terpengaruh dengan apa yang membuat ibunya terpengaruh dari kekuatan kehendak atau kelemahannya. Memberikannya nama yang baik, mengingat nama bagi seseorang adalah laksana baju yang memiliki pengaruh sugestif pada agama, perilaku, dan akhlaknya maka Rasulullah saw. Pun menegaskan agar anak-anak kaum muslimin dinamai dengan nama-nama indah yang mengekspresikan akidah isam dan nilai-nilainya. Nabi saw, sendiri sering mengganti nama yang jelek. Nama $A l$-ashi diganti karena berkonotasi maksiat, Al-aziz (yang maha perkasa), Al-hakam (yang maha menghukumi), dan nama-nama senada lainnya beliau ganti karena beberapa pertimbangan yang dituturkan para ulama sebagai berikut: "Nama $A l$-ashi diganti karena berkonotasi maksiat, padahal ciri seorang mukmin adalah taat dan pasrah kepada Allah. Al-aziz beliau ganti karena keperkasaan dan keagungan hanya milik Allah, dan motto seorang hamba adalah ketundukan dan kenistaan di hadapan Allah. Sementara Al-hakam berarti hakim yang tidak terbantahkan hukumnya, dan sifat ini jelas hanya berlaku bagi Allah sendiri.

\section{REFERENSI}

Abdullah, Abdurrahman Shaleh, 2005, Teori-Teori Pendidikan Berdasarkan al-Qur'an, Rineka Cipta, Jakarta.

Abdur Rahaman, Khalid, Al 'Akk, 1994, Shafwatul Bayaan li Ma'aanil Qur'anil Kariim, Daarul Basyaair, Damaskus, Bairut dan Darussalaam, Kairo, Mesir.

Ahmadi, Abu, 2008, Psikologi Perkembangan, Rineka Cipta Jakarta.

Ahmadi, Abu dan Joko Tri Prasetia, 1997, Strategi Belajar Mengajar, Pustaka Setia, Bandung.

Al-'Attas, Naquib, 2002, Konsep Pendidikan Islam, Mizan, Bandung.

Al-Abrasyi, M. Athiyah, 1990, DasarDasar Pokok Pendidikan Islam (terj.), Bulan Bintang, Jakarta.

Al-Attas, Syeikh Muhammad al-Naquib, 2000, Konsep Pendidikan Islam, Mizan, Bandung.

Al-Hasan, Yusuf Muhammad Al Hasan, tt, Mendidik Anak dalam Islam, ebook.

Ali, Muhammad, 1987, Penelitian Pendidikan Prosedur dan Strategi, Angkasa, Bandung.

Al-Jauhari, Mahmud Muhammmad, Muhammad Abdul Hakim Khayyal, 2005, Membangun Keluarga Qur'ani Panduan untuk Wanita Muslimah, Sinar Grafika Offset, Jakarta.

Al albani, Muhammad Nashiruddin, 1987, Mukhtashar Shahih al Imam al 
Bukhari, al Maktabah al Islami, Bairut, Dimasq.

An-Nahlawi, Abdurrahman, 2007, Pendidikan Islam: di Rumah, Sekolah dan Masyarakat, Gema Insani, Jakarta.

Arief, Armai, 2002, ilmu dan Metodologi Pendidikan Islam, Ciputat Press, Jakarta.

Arifin, HM., 2003, Ilmu Pendidikan Islam Tinjauan Teoritis dan Praktis Berdasarkan Pendekatan Interdisipliner, Bumi Aksara, Jakarta.

Arikunto, Suharsimi, 1991, Dasar-Dasar Evaluasi Pendidikan, Rajawali Press, Jakarta.

Azizy, Qodri, 2003, Pendidikan (Agama) untuk Membangun Etika Sosial, Aneka Ilmu, Semarang.

Azra. Azyumardi, 2005, Esei-esei Intelektual Muslim dan Pendidikan Islam, Logos Wacana Ilmu, Jakarta.

Sardiman A.M., 1986, Interaksi dan Motivasi Belajar Mengajar, Raja Wali, Jakarta.

Basya, Fahmi, 1427 H, Sains Spiritual Quran, SSQ Center.

Darajat, Zakiah et.al., 1996, Ilmu Pendidikan Islam, Bumi Aksara, Jakarta.

Departemen Agama RI, 2001, Metodologi Pendidikan Agama Islam, Direktorat Jenderal Pembinaan kelembagaan Agama Islam, Jakarta.
Dodson, Fitzhugh, 2003, Mendisiplinkan Anak dengan Kasih Sayang, Gunung Muli, Jakarta.

Don, Yahya, 2006, Psikologi sosial dalam pendidikan, PTS Professional Publishing, Selangor.

Ekabakti.

Fatah, Nanang, 2004, Landasan Manajemen Pendidikan, PT Remaja Rosdakarya, Bandung.

Gunarsa, Singgih D. 2000, Psikologi Perkembangan Anak dan Remaja, Gunung Mulia, Jakarta.

2002, Mendidik Anak Bersama Rasulullah, al-Bayan, Jakarta.

Halim, Muhyiddin Abdul, 2002, Kegelisahan Rasulullah Mendengar Tangis Anak, Mitra Pustaka, Jogjakarta.

Hurlock, Elizabeth. B. 1999, Perkembangan Anak, Diterjemahkan oleh Maitasaari Tjandrasa, Erlangga, Jakarta.

IAIN Sunan Ampel Malang, Tim Dosen, 1996, Dasar-Dasar Pendidikan Islam(Suatu Pengantar Ilmu Pendidikan Islam), Karya Aditama, Surabaya

Ilyas, Asnely. 2007, Mendambakan Anak Shale: Prinsip-Prinsip Pendidikan Dalam Islam, al-Bayan, Bandung.

Isa, Kamal Muhammad, 2003, Manajemen Pendidikan Islam, Fikahati Aneska, Jakarta.

Karel A., Steeinbrink, 1986; Pesantren, Madrasah, dan Sekolah: Pendidikan Islam Kurun Modern, LP3ES., Jakarta. 
Langguung, Hasan, 1992, Asas Asas Pendidikan Islam, Pustaka AlHusna, Jakarta.

Mastuhu, 1999, Memberdayakan Sistem Pendidikan Islam, Sekolah dan Keluarga, Logos Wacan Ilmu, Jakarta.

Mudyahardjo, Redja, 2004, Filsafat Ilmu Pendidikan: Suatu Pengantar, Rosdakaraya, Bandung.

Muhaimin, 2005, Pengembangan Kurikulum Pendidikan agama Islam: di Sekolah, Madrasah dan Perguruan Tinggi, Raja Grafindo Persada, Jakarta.

Muhaimin, et.al 2001, Paradigma Pendidikan Islam: Upaya Mengefektifkan Pendidikan Agama di Seklah, Remaja Rosdakarya, Bandung.

Muhammad bin Isa bin Surat at Turmudzi, Abi Isa, tt., Sunan At Turmudzi wa huwa al Jaami'ush Shahih, Toha Putra, Semarang, Indonesia.

Muthahari, Murthadda, 2001, Akhlak Suci yang Ummi: Sekolah Ilahi, Hikmah, Jakarta.

Qamar, Mujammil, 2005, “Epistemologi Pedidikan Islam: dari Metode Rasional hingga metode kritik", Erlangga, Jakarta.

Qutb, Sayyid, 2001, Tafsir fi Zilal alQur'an, Gema Insani Press, Jakarta.

Rahman, Jamal Abdurrahman, 2005, Tahapan Mendidik Anak Teladan Rasulullah Saw., Irsyad Baitus Salam, Bandung.

Ramayulis, 2006, Ilmu Pendidikan Islam, Kalam Mulia, Jakarta.
Rickard, Jenny; Hidayanti, Tantiarini, 2000, Relaksasi Untuk Anak-Anak, Gramedia Widiasarana Indonesia, Jakarta.

Saleh Abdullah, Abdurrahman, 1994, Teori-Teori Pendidikan Berdasarkan Al-Qur'an, Rineka Cipta, Jakarta.

Shaleh, Abdurrahman 2005, Pendidikan Agama dan Pembangunan watak Bangs,. Raja Grafindo Persada, Jakarta.

Shihab, M Quraish, Ihsan Ali-Fauzi, 2002, "Membumikan Al-Qur'an : Fungsi

Dan Peran Wahyu Dalam Kehidupan Masyarakat", Mizan, Bandung.

Soemanto, Wasty, 2000, "Psikologi Pendidikan : Landasan Kerja Pemimpin Pendidikan", Rineka Cipta, Jakarta.

Subaiti, Musa, 2003, "Akhlak Keluarga Muhammad Saw.", Lentera Baristama, Jakarta.

Tafsir, Ahmad, 1994, Ilmu Pendidikan Dalam Persfektif Islam, Remaja Rosda Karya, Bandung

Virginia, Alexandria. 2008, "Teaching Good Behavior", Virginia: Time Life Http://WWW.Taujih Online, Kharisma. Membiasakan Anak Disiplin dan Mandiri Sejak Kecil. Diakses tanggal 20 April 2006.

Widodo, Sembodo Ardi, 2007, "Kajian Filosofis Pendidikan Barat dan Islam", Nimas Multima, Jakarta

Wijanarko, Jarot, 2005, "Mendidik Anak: Untuk Meningkatkan Kecerdasan Emosional Dan Spiritual", Gramedia Pustaka Utama, Jakarta. 